\title{
Mechanical endonasal dacryocystorhinostomy with mucosal flaps
}

\author{
A Tsirbas, P J Wormald
}

Br J Ophthalmol 2003;87:43-47

Aims: To describe and assess the efficacy of mechanical endonasal dacryocystorhinostomy (MENDCR). This is a new technique that involves creation of a large rhinostomy and mucosal flaps. The study involved a prospective nonrandomised interventional case series with short perioperative follow up.

Method: A prospective series of 104 consecutive endonasal DCRs performed from January 1999 to December 2001 were entered into the study. Patients included in the study had nasolacrimal duct obstruction and had not had previous lacrimal surgery. The technique involved anastomosis of nasal mucosal and lacrimal sac flaps and a large bony ostium. Surgery was performed by two surgeons (AT/PJW). Follow up assessment included nasoendoscopy as well as symptom evaluation. Success was defined as anatomical patency with fluorescein flow on nasoendoscopy and patency to lacrimal syringing. The average follow up time was 9.7 months (range 2-28, SD 6.7 months).

Results: There were 104 DCRs performed on 86 patients ( 30 male, 56 female). The average age of the patients was 59 years (range 3-89, SD 24.1 years). Common presentations were epiphora (77\%) and/or mucocele (19\%). Septoplasty (SMR) was required in 48 DCRs (46\%) and 13 DCRs $(12.5 \%)$ needed other endoscopic surgery in conjunction with the lacrimal surgery. The surgery was successful in 93 cases $(89 \%)$. Of the 11 cases that were classified as a failure six patients was anatomically patent but still symptomatic and another two had preoperative canalicular problems. The anatomical patency with this new technique was thus 95\% (99 of 104 DCRs).

Conclusion: MENDCR involves creation of a large ostium and mucosal preservation for the construction of flaps. The anatomical success is $95 \%$ and is similar to external DCR and better then other endonasal approaches. The authors suggest that creation of a large ostium as well as mucosal flaps improves the efficacy of this endonasal technique.

$\mathrm{D}$ acryocystorhinostomy (DCR) is an operation that has been used for the past 100 years. The original intranasal approach was described in 1893 by Caldwell ${ }^{1}$ and the external approach in 1904 by Toti. ${ }^{2}$ The external approach became very popular and the mainstay of treatment with modification in the $1920 \mathrm{~s}^{3}$ with the addition of flaps, and in 1962 with silastic tube intubation by Jones. ${ }^{4}$ The intranasal approach was largely abandoned owing to problems with visualisation but with modern endoscopes and rhinology instruments there has been renewed interest in the past 10 or so years. McDonogh and Meiring ${ }^{5}$ described the first modern endonasal DCR procedure in 1989 with Massaro et al ${ }^{6}$ in 1990 using an argon laser for the osteotomy. In 1991 Gonnering et al used an endoscope with the argon laser, rather than the operating microscope, for completing the endonasal procedure.
Many ophthalmologists still believe that external DCR is the gold standard treatment for nasolacrimal duct obstruction $(\mathrm{NLDO})^{8}$ with success rates of $90 \%+$ reported. ${ }^{9}$

Currently endoscopic DCR can be performed with laser assistance $^{10}{ }^{11}$ or other methods to remove bone and mucosa including powered drills, ${ }^{12}$ punches, ${ }^{13}$ and radio surgical electrodes. ${ }^{14}$ Laser assisted DCR (ENLDCR) has success rates which vary from $60 \%$ to $86 \%,{ }^{10}{ }^{11}$ whereas endonasal DCR with other tools ("cold steel") seems to have a slightly higher success rate. ${ }^{12} 13$

Most previous procedures involved sacrificing the nasal mucosa and removing the medial wall of the sac. We describe an approach that involves preservation of nasal mucosa and the cutting of anterior and posterior flaps in the lacrimal sac in order to achieve mucosal and lacrimal sac anastomosis at the end of the procedure. The flaps are not sutured but closely apposed. This leads to the marsupialisation of the sac on the lateral nasal wall rather than creation of an ostium into the sac. To achieve lacrimal sac marsupialisation complete exposure of the sac is necessary. Until a recent publication ${ }^{15}$ the intranasal anatomy of the lacrimal sac was not fully understood. ${ }^{16}$ The upper half of the sac lies above the insertion of the middle turbinate on the lateral nasal wall. This puts it behind the thick bone of the frontal process of the maxilla. To fully expose this area the use of a drill is necessary. Only the inferior posterior part of the sac is covered by the thin lacrimal bone.

\section{MATERIALS AND METHODS}

Consecutive patients undergoing primary DCR from January 1999 to December 2001 were included in the study. Patients' standard preoperative evaluation included investigation using lacrimal irrigation. Jones test and endoscopy of the nasal cavity were also performed. Dacryocystography and lacrimal scintillography was done on all patients. It was possible to assess the need for concurrent septoplasty (SMR) preoperatively. If the middle turbinate is not visible with the endoscope preoperatively owing to a septal deviation or spur then access is tight and DCR with septoplasty is needed. A large capacious nasal cavity with easy view of middle turbinate suggests MENDCR can be performed without SMR. Any lower lid problems or previous lacrimal trauma were exclusion criteria.

There were 86 patients who underwent 104 endoscopic DCR procedures all using the same technique performed by two main surgeons (PJW, AT). Thirty nine patients had a left DCR, 29 a right DCR, and 18 patients bilateral DCRs. There were 56 female and 30 male patients aged 59 years (range 3-89, SD 24.1 ). Acute or chronic dacryocystitis was a feature in $14 \%$ of patients and mucocoele in $20 \%$ (Table 1 ).

Patients who required other nasal procedures were included in the analysis. These included septoplasty (SMR), which was often necessary to perform the DCR, as well as other endoscopic surgery. Middle meatal antrostomy for sinus disease was the commonest ancillary procedure performed. Infrequently, uncinectomy or inferior turbinectomy was 
Table 1 Demographics of study group

\begin{tabular}{|c|c|c|c|c|}
\hline Characteristics & Primary DCR & $\begin{array}{l}\text { Primary DCR with } \\
\text { septoplasty }\end{array}$ & $\begin{array}{l}\text { Primary DCR+ ancillary } \\
\text { nasal procedures }\end{array}$ & Total \\
\hline Operations/patients & $43 / 37$ & $48 / 38$ & $13 / 11$ & $104 / 86$ \\
\hline Male & 14 & 9 & 7 & 30 \\
\hline Female & 23 & 29 & 4 & 56 \\
\hline \multicolumn{5}{|l|}{ Laterality of surgery } \\
\hline Left & 20 & 16 & 3 & 39 \\
\hline Right & 11 & 12 & 6 & 29 \\
\hline Bilateral & 6 & 10 & 2 & 18 \\
\hline
\end{tabular}

performed. Some patients in this analysis have been included in a previous pilot study. ${ }^{17}$ Informed consent was obtained from all patients

\section{Surgical technique}

The nasal mucosa was decongested with pledgets soaked in $10 \%$ cocaine. The lateral nasal wall and head of the middle turbinate (MT) were injected with local anaesthetic ( $2 \%$ Xylocaine with 1:80 000 adrenaline (Astra Pharmaceuticals, N Ryde, Sydney, Australia)). The $30^{\circ}$ Storz (Storz, St Louis, MI, USA) endoscope with three chip camera was used for the entire operation, except when a septoplasty was required in which case the zero degree scope was used.

A mucosal flap, hinged posteriorly, was elevated from the lateral nasal wall to expose the frontal process of the maxilla and its articulation with the lacrimal bone. The incision for the mucosal flap begins $8 \mathrm{~mm}$ above the insertion of the middle turbinate and is brought horizontally forward $8 \mathrm{~mm}$ anterior to the middle turbinate. It is taken vertically down to just above the insertion of the inferior turbinate before taking it posteriorly up to the insertion of the uncinate process. The mucosal flap is elevated exposing the junction of the hard frontal process of the maxilla and the thin soft lacrimal bone. The lacrimal bone was peeled off the inferior half of the lacrimal sac. A Hajek-Koeffler forward biting punch (Martin, Tutligen, Germany) was then used to remove the frontal process of the maxilla which overlies the anterior part of the inferior lacrimal sac. The bone over the superior nasolacrimal duct was also removed. Bone removal is continued superiorly till the bone becomes too thick for the punch. A curved 15 degree diamond burr attached to a powered microdebrider (Medtronic Xomed, Jacksonville, FL, USA) is used to remove the rest of the frontal process of the maxilla still covering the anterior sac. This powered bone removal is continued superiorly above the attachment of the MT to remove bone that covers the fundus of the sac. Usually the agar nasi cell is exposed as the fundus extends above the MT axilla. The entire sac should be exposed. The medial wall of the sac is then tented with a Bowman's probe (Visitec, Warwickshire, UK) to ensure all the bone over the common canalicular opening (CCO) has been removed. It is important to ensure that all bone over the CCO up to the fundus of the sac is removed, as this will allow the sac flaps to sit flatter on the lateral nasal wall. The medial wall of the sac is the incised vertically to create a large anterior and smaller posterior flap. Small horizontal cuts are made in these flaps superior and inferior so they can be reflected onto the lateral nasal wall without any tension. Once the lacrimal sac flaps have been positioned on the lateral nasal wall the nasal mucosal flap is trimmed into a " $\mathrm{C}$ " shape. It forms a superior and inferior flap extending anteriorly from the posterior hinge. When reflected back onto the lateral nasal wall the " $\mathrm{C}$ " shape of the nasal mucosal flaps fits around the opened lacrimal sac so that the mucosal edges are closely apposed. Usually only a small area of exposed bone anteriorly on the frontal process of the maxilla is not covered by mucosa (see Fig 1).
The lacrimal system is then intubated and a small gel foam patch is used to keep the flap anastomosis in position for the initial healing period. Postoperatively, oral antibiotics for 5 days (amoxicillin and clavulanic acid 500/125 three times daily) and topical antibiotics (chloramphenicol drops) were given. A saline moisturising spray was also used for 6 weeks to help stop mucosal drying in the acute postoperative period. All surgery was performed on a day case, outpatient basis. Follow up of patients was at 1, 3, 6, 12, 24, and 39 months with the average follow up being 9.7 months (2-28 months) after removal of tubes. All except two patients received intubation. Tubes were usually removed at the first postoperative visit at 4-8 weeks. Average intubation time was 6.1 weeks (range 2-52 weeks, SD 7.1 weeks).

Most patient underwent surgery with general anaesthesia (81 of 86 patients). In 101 of the 104 DCR operations it was possible to create a good sized opening in the lacrimal sac with approximation of the flaps. After removal of tubes the patients were assessed with rigid nasal endoscopy and fluorescein dye passage. Morphological assessment of the ostium and syringing of the lacrimal system was also done. Patients were assessed in terms of anatomical patency as well as symptom relief.

\section{RESULTS}

In the current study a well healed marsupialised ostium was seen in 99 of 104 cases (95\%). There was free flow to the nose when one drop of $2 \%$ fluorescein was put in the conjunctival sac. The nasolacrimal system was also patent to syringing via the lacrimal puncta. In five of the 104 cases there was scarring of the ostium at the sac-nasal mucosal anastomosis visible on endoscopy. Neither fluorescein drainage nor lacrimal syringing was possible. These five patients had epiphora similar to their preoperative complaint. Six patients were symptomatic with a patent system and a well healed ostium. Five of these patients complained of epiphora preoperatively but were patent to syringing and on dacryocystography and one patient had anatomical nasolacrimal duct obstruction preoperatively. The overall success rate was then $89 \%$ (93 of 104 DCRs). All these six patients showed a well healed ostium on endoscopy but complained of occasional epiphora especially on windy days. In these patients fluorescein was seen to drain into the nose on endoscopy and lacrimal syringing was achieved without undue pressure generation. Hence the anatomical success rate was 99 of 104 case (95\%) (Table 2 ).

Approximately $46 \%$ of cases (48 of 104) required a septoplasty at the time of surgery which is higher than other studies of endonasal DCR, but the creation of a large ostium necessitates better access than is often required with other procedures. $^{18}{ }^{19}$ About $12.5 \%$ of cases (13 of 104) required endoscopic sinus surgery in conjunction with DCR, a rate seen in other studies. ${ }^{20}$

There were three cases of postoperative haemorrhage. These resolved with nasal packing and did not need transfusion. This gives a rate of less than 3\% which compares well with both previous endonasal studies ${ }^{21}$ and external DCR studies. ${ }^{22}$ There 


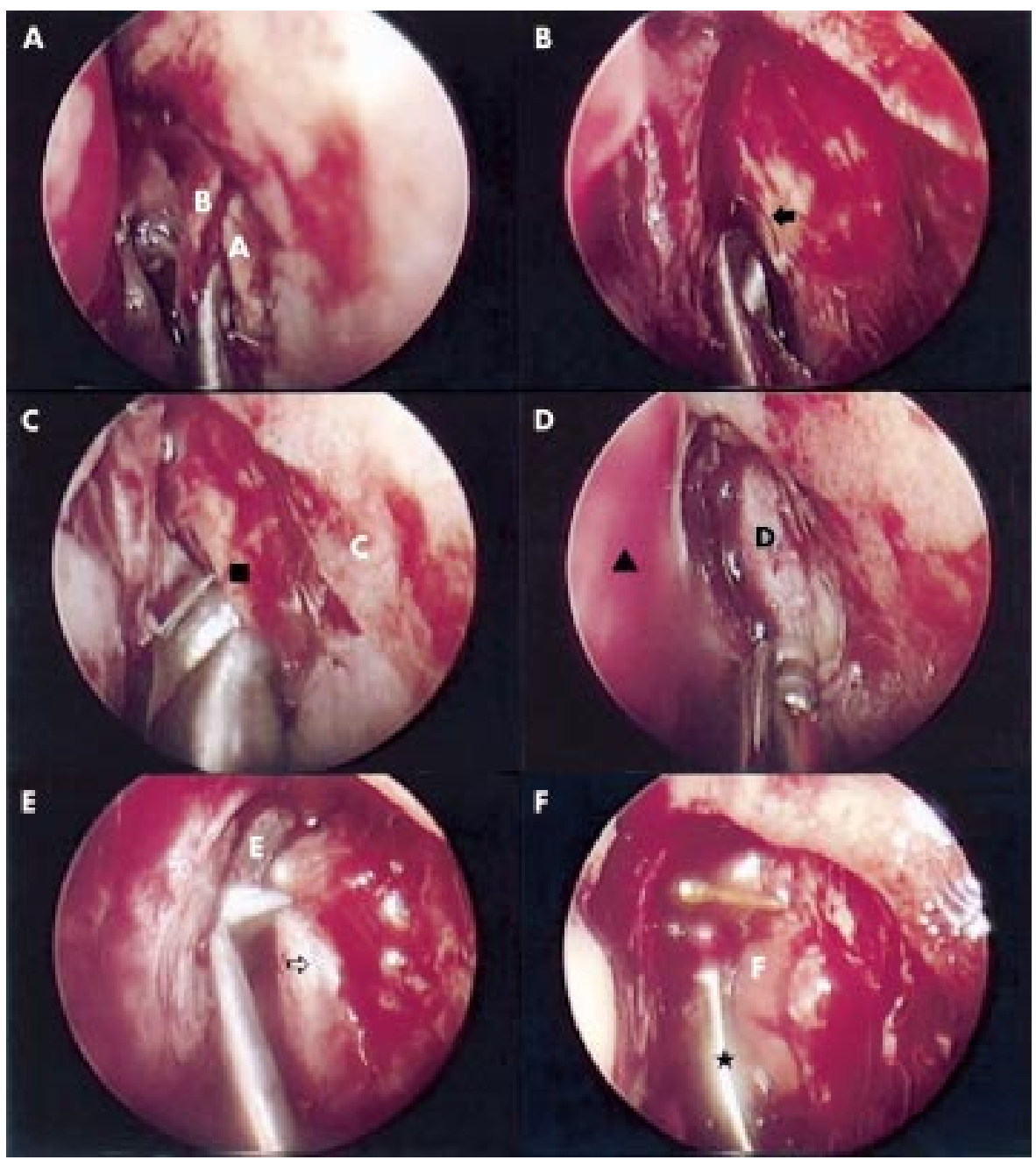

Figure 1 Mechanical endonasal DCR procedure. (A) A, frontal process of maxilla; B, nasal mucosal flap elevation. (B) Junction of frontal process maxilla and lacrimal bone (arrow). (C) C, lateral nasal wall; black square, punch on frontal process of maxilla. (D) D, lacrimal sac; arrowhead, nasal septum. (E) E, agar nasi cell; arrow, medial wall lacrimal sac, (F) F, opened lacrimal sac; asterisk, folding back of posterior lacrimal sac flap.

\begin{tabular}{lll} 
Table 2 & Surgical results & \\
\hline & Success & \\
\cline { 2 - 3 } & Total & $\begin{array}{l}\text { Excluding } \\
\text { canalicular } \\
\text { pathology }\end{array}$ \\
\hline $\begin{array}{l}\text { Anatomical patency } \\
\begin{array}{l}\text { Anatomical patency and symptom } \\
\text { relief }\end{array}\end{array}$ & $99 / 104(95 \%)$ & $99 / 102(97 \%)$ \\
\hline
\end{tabular}

were no cases of orbital fat exposure or frontal sinusitis which can occur if the dissection is taken too posteriorly into the uncinate. ${ }^{21}$ Damage to the orbital plate of the ethmoid (lamina papyracea) and frontonasal duct can occur if the dissection is taken too posterior.

In 102 of 104 cases O'Donohue tubes were used for lacrimal intubation.

The average follow up was 9.7 months (range 2-28). Follow up of these patients is still ongoing.

\section{DISCUSSION}

There has been concern over many years that endoscopic DCR is not as successful as external DCR. ${ }^{82}{ }^{24}$ There are very few prospective randomised trials in the literature. A study by Hartikainen $e a^{9}$ in 1998 had a 1 year success rate of $75 \%$ for endonasal DCR as opposed to $91 \%$ for conventional external DCR. These investigators used non-laser tools to remove bone in the lacrimal fossa. Other investigators in the literature have used various lasers to create the rhinostomy.

Currently endonasal approaches can be divided into endonasal laser assisted DCR (ENLDCR), ${ }^{725}$ endocanalicular laser assisted DCR (ECLDCR), ${ }^{126} 27$ and powered mechanical endonasal DCR (MENDCR), or "cold steel" DCR, with"12 or without drills. ${ }^{21} 28$

The present study has an anatomical success rate of $95 \%$, with success strictly defined in both anatomical and symptomatic terms. Patients were assessed for fluorescein drainage to the nose when a drop was placed in the conjunctival sac. This has been shown to be a good, accurate test for functional performance of a patent DCR. ${ }^{29}$

The main difference between the presented technique and previously described techniques is the creation of a large bony ostium and mucosal apposition with the creation of mucosal and lacrimal flaps.

Since the early 1990s laser assisted DCR (ENLDCR) has grown in popularity but the long term success has not been high enough to convince many ophthalmologists to adopt the technique. The main problem with ENLDCR is the difficulty removing the thick bone of the frontal process of the maxilla. 
Most lasers can only create a $5-8 \mathrm{~mm}$ osteotomy as they are only removing the thin lacrimal bone at the posterior inferior aspect of the lacrimal sac. Even though some authors ${ }^{30}$ have suggested ostium size is unimportant we believe this is not the case. The creation of a large ostium allows the room to fashion an anastomosis of the lacrimal mucosa with the mucosa of the nasal cavity. Anatomical studies ${ }^{15}$ have shown that the lacrimal sac is lateral to the head of the middle turbinate superiorly and its anteroinferior aspect is under the frontal process of the maxilla (other investigators have placed the sac lower on the lateral nasal wall). ${ }^{16}{ }^{31}$ Both these areas have very thick bone that is not amenable to removal by laser or rongeurs. If an attempt is made to remove this thick bone with a laser excessive heat is generated which may increase tissue damage and postoperative scarring. This may be one of the reasons for the decreased long term success of ENLDCR ${ }^{101825}$ and ECLDCR. ${ }^{32}$ The technique described in this study uses simple punches and a drill attached to a nasal microdebrider to remove all the bone covering the lacrimal sac and upper part of the nasolacrimal duct creating an osteotomy of around 20 $\mathrm{mm} \times 15 \mathrm{~mm}$. This is a much larger removal of bone than seen in other endonasal approaches. The large osteotomy allows wide exposure of the lacrimal sac and allows the creation of mucosal flaps, which replicates nasal and sac mucosal apposition seen with external DCRs. A large ostium at the time of surgery correlates with a large opening intranasally postoperatively. ${ }^{33}$ Figure 2 shows a well marsupialised ostium.

It is important to note that much of the sac lies above the level of the axilla of the middle turbinate, ${ }^{15}$ contrary to other authors suggesting that the sac is anterior to or below the insertion of the middle turbinate with little extension above it. ${ }^{7031}$ The bone covering this superior part of the sac is very thick and has an intimate relation with the agar nasi cell medially. In addition, it is important to recognise that the posterior aspect of the lacrimal sac is adjacent to the uncinate, ${ }^{3435}$ and that this structure should be preserved. Going posterior to this landmark leads to an increased risk of orbital fat prolapse or haematoma ${ }^{12}$ in addition to compromising the natural ostium of the maxillary sinus. The uncinate was preserved in all cases undergoing only a DCR and removed only in patients who underwent additional endoscopic sinus surgery for chronic sinusitis not related to their lacrimal symptoms. It has been suggested that the uncinectomy needs to be done as the first step $^{36}$ to endonasal DCR. This is not necessary as the frontal process of the maxilla is a constant intranasal landmark that abuts the thin lacrimal bone below the insertion of the middle turbinate into the lateral nasal wall. The junction of the hard frontal process of the

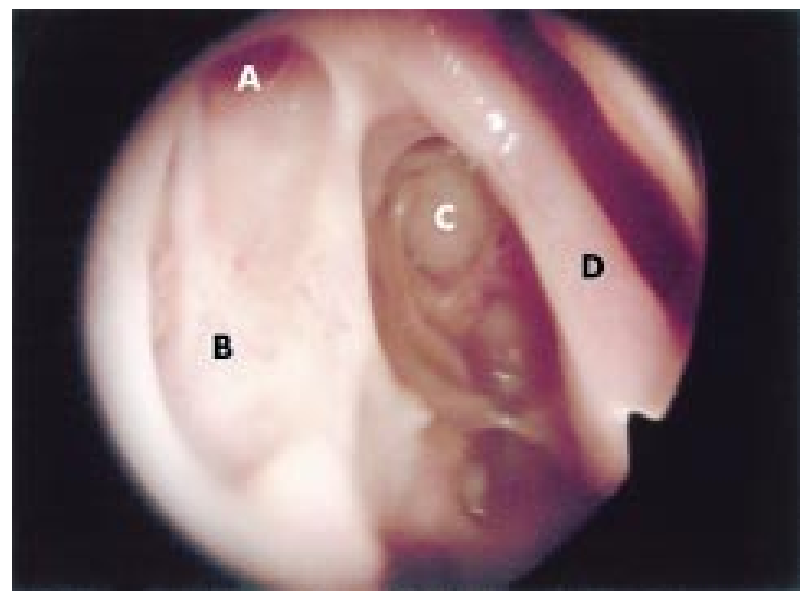

Figure 2 Marsupialised lacrimal sac. A, common canalicular opening on lateral nasal wall. B, marsupialised lacrimal sac on lateral nasal wall. C, opened agar nasi cell. D, middle turbinate. maxilla and the thin lacrimal bone is the first landmark that is sought during the presented technique but it can only be visualised with a 30 degree endoscope in the majority of patients. The uncinate process is in a posterior relation to the lacrimal bone and as such does not need removal to expose the lacrimal sac. To fully expose the sac the thick bone of the frontal process of the maxilla needs to be removed, as does the bone superior to the lacrimal bone. This often necessitates removal of the anterolateral wall of the agar nasi cell. Once the sac is opened the common canalicular opening is used as a landmark to ensure adequate exposure of the sac. It is important to open the lacrimal sac with "cold steel" to avoid risks of contracture and scarring. ${ }^{32}$ The creation of anterior and posterior flaps in the lacrimal sac mucosa allows primary intention healing with the nasal mucosal flaps, thus marsupialising the sac into the lateral nasal wall. Poor or minimal preservation of mucosa may lead to increased granulation and fibrosis. ${ }^{37}$ This approach preserves the general principles of creating a mucosal lined fistula so important in external DCR surgery. ${ }^{8}$ Postoperative scarring at the site of the rhinostomy is one of the major causes of DCR failure, ${ }^{8}$ both with external and ENLDCR $^{38} 39$ techniques. In our current study five patients had scarring of the osteotomy that led to failure of the surgery. Several studies ${ }^{12} 23^{40}$ have suggested that a dependent ostium position is vital to increase success in external and endonasal surgery. Complete exposure and marsupialisation of the sac with adequate bone removal obviates concern about ostium position that may occur with other techniques. Recently several investigators ${ }^{41}{ }^{42}$ have used mitomycin $\mathrm{C}$ to improve success rates with ENLDCR and some success rates seem close to $100 \%{ }^{43}$ If the whole of the lacrimal sac is not exposed and the rhinostomy is small this may have a future role in preventing closure of the ostium.

Many studies of ENLDCR exclude cases in which nasal access is difficult. It is important to have some endonasal training and have an intimate knowledge of the nasal anatomy before attempting this technique. Many investigators use a light pipe inserted through the canaliculi to identify the intranasal position of the sac. During our studies septoplasty (SMR) to improve access to the axilla of the middle turbinate was necessary in $46 \%$ of cases. It is important that the ophthalmologist train in this area before attempting this technique. This high percentage relates to the increased access needed with this approach. Only minimal access is needed in ENLDCR to remove the lacrimal bone.

An additional advantage of MENDCR was the preservation of lacrimal pump function. This was easily visualised with the endoscope by observing fluorescein being pumped into the nose with each blink (see Fig 3). Previous studies have shown that successful endonasal DCR patients are more likely to have

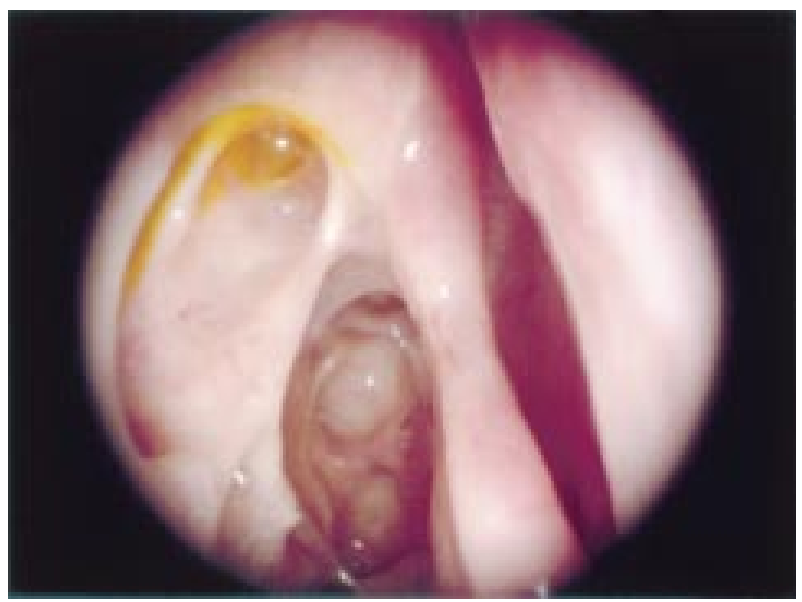

Figure 3 Fluorescein flow into the nose. 
positive scintillography when compared to successful external DCR patients. ${ }^{923}$ The attachments of the orbicularis to the lateral wall of the lacrimal sac are not disturbed with this approach and this may help preserve some lacrimal pump function..

\section{CONCLUSIONS}

For the past decade many types of endonasal approaches have been tried. Generally the long term success rates have not been equivalent to that achieved with external DCR. The technique we describe encompasses important differences to previously described methods. It involves creation of a large rhinostomy and the preservation of lacrimal sac and nasal mucosa to create mucosal flaps. This mucosal preservation and apposition help to marsupialise the lacrimal sac onto the lateral nasal wall.

Good anatomical knowledge of intranasal structures allows accurate mucosa preserving surgery. Endoscopic skills are necessary to ensure accurate and reproducible surgery.

The technique described has a success rate of $89 \%$ and the anatomical success rate is $95 \%$. These results are similar to those obtained for both external DCR as well as for other endonasal approaches.

\section{ACKNOWLEDGEMENT}

PJ Wormald receives royalties from Medtronic Xomed for instruments

There are no known conflicts of interest or outside funding sources for this article.

\section{Authors' affiliations}

A Tsirbas, Department of Ophthalmology, Flinders Medical Centre and Queen Elizabeth Hospital, Adelaide, South Australia P J Wormald, Department of Surgery-Otorhinolaryngology, Queen Elizabeth Hospital and Royal Adelaide Hospital, Adelaide, South Australia

Correspondence to: Dr A Tsirbas, Department of Ophthalmology, Flinders Medical Centre, Beford Park, SA 5042, Australia;

Ophthalmology@fmc.sa.gov.au

Accepted for publication 13 August 2002

\section{REFERENCES}

1 Caldwell GW. Two new operations for obstruction of the nasal duct, with preservation of the canaliculi, and with an incidental description of a new lachrymal probe. Am J Ophthalmol 1893;10:189-93.

2 Toti A. Nuovo Metodo conservatore dicura radicale delle suppurazione croniche del sacco lacrimale (dacricistorhinostomia). Clin Moderna (Firenza) 1904;10:385.

3 Dupuy-Dutemp L, Bouguet, M. Note preliminaire sur en procede de dacryocystorhinostomie. Ann Ocul 1921;158:241

4 Jones LT. The cure of epiphora due to canalicular disorders, trauma and surgical failures on the lacrimal passages. Trans Am Acad Ophthalmol Otolaryngol 1962;66:506.

5 McDonogh M, Meiring JH. Endoscopic transnasal dacryocystorhinostomy. J Laryngol Otol 1989;103:585-7.

6 Massaro BM, Gonnering RS, Harris, GJ. Endonasal laser dacryocystorhinostomy. A new approach to nasolacrimal duct obstruction. Arch Ophthalmol 1990;108:1172-86.

7 Gonnering RS, Lyon DB, Fisher JC. Endoscopic laser-assisted lacrimal surgery. Am J Ophthalmol 1991;111:152-7.

8 Welham RA, Wulc AE. Management of unsuccessful lacrimal surgery. $\mathrm{Br}$ J Ophthalmol 1987;71:152-7.

9 Hartikainen J, Jukka A, Matti V, et al. Prospective randomised comparison of endonasal endoscopic dacryocystorhinostomy and external dacryocystorhinostomy. Laryngoscope 1998;108:1861-6.

10 Bakri SJ, Carney AS, Downes RN, et al. Endonasal laser-assisted dacryocystorhinostomy. Hosp Med 1998;59:210-15.
11 Muellner K, Bodner E, Mannor GE, et al. Endolacrimal laser assisted surgery. Br J Ophthalmol 2000;84:16-18.

12 Lun Sham C, van Hasselt AC. Endoscopic terminal dacryocystorhinostomy. Laryngoscope 2000;1 10:1045-9.

13 McDonogh M. Endoscopic transnasal dacryocystorhinostomy. S Afr J Surg 1992;30:107-10.

14 Javate RM, Campornanes BS, Nelson D, et al. The endoscope and the radiofrequency unit in DCR surgery. Ophthal Plastic Reconstr Surg $1995 ; 11: 54-8$

15 Wormald PJ, Kew J, Van Hasselt CA. The intranasal anatomy of the naso-lacrimal sac in endoscopic dacryocystorhinostomy. Otol Head Neck Surg 2000; 123:307-10.

16 Rebeiz EE, Shapshay SM, Bowlds JH, et al. Anatomic guidelines for dacryocystorhinostomy. Laryngoscope 1992;102:1181-4.

17 Wormald.PJ. Powered endonasal dacryocystorhinostomy. Laryngoscope 2002;112:69-72.

18 Metson R. Endoscopic surgery for lacrimal obstruction. Otolaryngol Head Neck Surg 1991;104:473-9.

19 Pearlman SJ, Michalos P, Reib ML, et al. Translacrimal transnasal laser-assisted dacryocystorhinostomy. Laryngoscope 1997; 107:1362-5.

20 Sadiq SA, Hugkulstone CE, Jones NS, et al. Endoscopic holm: YAG laser dacryocystorhinostomy. Eye 1996;10:46.

21 Sprekelsen MB, Barberan MT. Endoscopic dacryocystorhinostomy: surgical technique and results. Laryngoscope 1996;106:187-9.

22 Tsirbas A, McNab AA. Secondary haemorrhage in dacryocystorhinostomy. Clin Exp Ophthalmol 2000;28:22-5.

23 Ibrahim HA, Batterbury M, Banhegyi G, et al. Endonasal laser dacryocystorhinostomy and external dacryocystorhinostomy outcome profile in a general ophthalmic service unit; a comparative retrospective study. Ophthalmic Surg Lasers 2001;32:220-7.

24 Hurwitz JJ, Merkur S, DeAngelis D. Outcome of lacrimal surgery in older patients. Can J Ophthalmol 2000;35:18-22

25 Hehar SS, Jones NS, Sadiq SA, et al. Endoscopic holmium:YAG laser dacryocystorhinostomy-safe and effective as a day-case procedure. J Laryngol Otol 1997;111:1056-9.

26 Rosen N, Barak A, Rosner M. Transcanalicular laser-assisted dacryocystorhinostomy. Ophthal Surg Lasers 1997;28:723-6.

27 Caversaccio $M$, Frenz M, Schar $P$, et al. Endonasl and transcanalicular Er;YAG laser dacryocystorhinostomy. Rhinology 2001;39:28-32.

28 Cokkeser Y, Evereklioglu C, Hamdi E. Comparative external versus endoscopic dacryocystorhinostomy: results in 115 patients (130 eyes) Otolaryngol Head Neck Surg 2000;123:488-91.

29 Becker BB. Nasal endoscopy in dye testing after dacryocystorhinostomy Ophthalmic Plast Reconst Surg 1990;6:64-7.

30 Linberg JV, Anderson RL, Busted RM, et al. Study of intranasal ostium external dacryocystorhinostomy. Arch Ophthalmol 1982;100:1758-62.

31 Calhoun KH, Rotsler WH, Stiernberg CM. Surgical anatomy of the lateral nasal wall. Otolaryngol Head Neck Surg 1990;102:156-60.

32 Mullner K, Wolf G. Endoscopic treatment of lacrimal duct stenoses using a KTP laser-report of initial experience. Klin Monatsbl Augenheilkd 1999:215:28-32.

33 Ezra E, Restori M, Mannor G, et al. Ultrasonic assessment of rhinostomy size following external dacryocystorhinostomy. Br J Ophthalmol 1998;82:786-9.

34 Unlu HH, Govsa F, Mutlu C, et al. Anatomical guidelines for intranasal surgery of the lacrimal drainage system. Rhinology 1997;35:11-15.

35 Unlu HH, Goktan C, Aslan A, et al. Injury to the lacrimal apparatus after endoscopic sinus surgery; surgical implications from active transport dacryocystography. Otolaryngol Head Neck Surg date;124:308-12.

36 Fayet B, Racy E, Assouline M. Systematic unciformectomy for a standardised endonasal dacryocystorhinostomy. Ophthalmology 2002; 109:530-6.

37 Onerci $M$, Orhan $M$, Ogretmenoglu $O$, et al. Long term results and reasons for failure of intranasl endoscopic dacryocystorhinostomy. Acta Otolaryngol 2000;1 20:319-22.

38 Woog JJ, Kennedy RH, Custer PL, et al. Endonasal dacryocystorhinostomy - a report by the American Academy of dacryocystorhinostomy-a report by the American Acader
Ophthalmology. Ophthalmology 2001;108:2369-77.

39 Steadman MG. Transnasal dacryocystorhinostomy. Otolaryngol Clin N Am 1985;8:107-11.

40 Ibrahim HA, Noble JL, Batterbury M, et al. Endoscopic-guided trephination dacryocystorhinostomy (Hesham DCR). Ophthalmology 2001; 108:2337-46.

41 Ugurbas SH, Zilelioglu G, Sargon MF, et al. Histopathologic effects of mitomycin-C on endoscopic transnasal dacryocystorhinostomy. Ophthal Surg Lasers 1997;28:300-4.

42 Liao SL, Kao SCS, Tseng JHS, et al. Results of intraoperative mitomycin $\mathrm{C}$ application in dacryocystorhinostomy. $\mathrm{Br} J$ Ophthalmol 2000;84:903-6.

43 Camara JG, Bengzon AU, Henson RD. The safety and efficacy of mitomycin $\mathrm{C}$ in endonasal endoscopic laser assisted dacryocystorhinostomy. Ophthal Plast Reconstr Surg 2000;16:114-18. 